\title{
Vitamin D deficiency is associated with urinary tract infection in children
}

\author{
Sherein Abdelhamid Shalaby ${ }^{1}$, Nesrein Mosad Handoka², Rasha Emad Amin ${ }^{3}$
}

\author{
${ }^{1}$ Department of Pediatrics, Faculty of Medicine, Suez Canal University, Ismailia, Egypt \\ ${ }^{2}$ Department of Pediatrics, Faculty of Medicine, Port Said University, Port Said, Egypt \\ ${ }^{3}$ Department of Clinical and Chemical Pathology, Faculty of Medicine, Port Said \\ University, Port Said, Egypt
}

Submitted: 27 April 2016

Accepted: 11 July 2016

Arch Med Sci 2018; 14, 1: 115-121

DOI: 10.5114/aoms.2016.63262

Copyright $\odot 2016$ Termedia \& Banach

\author{
Corresponding author: \\ Dr. Sherein Abdelhamid \\ Shalaby MSc, MD \\ Department of Pediatrics \\ Faculty of Medicine \\ Suez Canal University \\ Ismailia, Egypt \\ Phone: +201093266656 \\ E-mail: shalaby25@hotmail. \\ com
}

\begin{abstract}
Introduction: In humans, vitamin D has been shown to play a role in infectious diseases, but its association with acquisition and a complicated course of febrile urinary tract infections (UTIs) has not been investigated. We aimed to investigate the association between 25 -hydroxyvitamin $D\left(25(\mathrm{OH}) \mathrm{D}_{3}\right)$ levels and the risk of first time febrile UTI in children.

Material and methods: This prospective case-control study included 50 children with first febrile UTI, with no risk factors for UTI, and 50 age- and sexmatched healthy siblings as controls. White blood cell count, serum C-reactive protein, calcium, phosphorus, alkaline phosphatase and parathormone were measured in all studied children. Vitamin D status was determined by measuring plasma $25(\mathrm{OH}) \mathrm{D}_{3}$ level. Deficiency was defined as a plasma $25(\mathrm{OH}) \mathrm{D}_{3}$ level $\leq 25 \mathrm{nmol} / \mathrm{l}$.

Results: Children with UTI had significantly lower mean serum levels of $25(\mathrm{OH}) \mathrm{D}_{3}(10.5 \pm 2.7 \mathrm{nmol} / \mathrm{l})$ than those of controls $(25.9 \pm 5.6 \mathrm{nmol} / \mathrm{l})$ $(p<0.05)$. Patients with lower UTI had significantly higher serum levels of $25(\mathrm{OH}) \mathrm{D}_{3}$ compared to those with acute pyelonephritis $(12.4 \pm 2.59$ vs. $8.2 \pm 3.2 \mathrm{nmol} / \mathrm{l} ; p<0.001)$. Mean serum levels of $25(\mathrm{OH}) \mathrm{D}_{3}$ were significantly lower $(p=0.001)$ in the female patients compared with males, and this difference was not found within the control group. Multivariate analysis showed that a serum $25(\mathrm{OH}) \mathrm{D}_{3}$ level of $\leq 25 \mathrm{nmol} / \mathrm{l}$ is associated with UTI $(\mathrm{OR}=1.94,95 \% \mathrm{Cl}: 1.61-2.82 ; p=0.04)$.
\end{abstract}

Conclusions: Vitamin $D$ deficiency $(\leq 25 \mathrm{nmol} / \mathrm{l})$ was an independent risk factor for UTI in children.

Key words: children, urinary tract infection, 25-hydroxyvitamin D, vitamin D deficiency.

\section{Introduction}

In children, one of the most common sites of infection is the urinary tract [1]. Urinary tract infection (UTI) in the pediatric population is a known cause of acute morbidity and chronic sequences in contrast to its uncomplicated course in adults [2].

During the first 6 months of life, infants who have had UTIs show generalized manifestations, especially fever, vomiting, and decreased activity. The lack of clinically reliable signs at this age greatly limits the usefulness of physical examination as a diagnostic tool in these young patients. As a result, even in cases where there is an evidenced extrarenal source of 
infection, UTI should be ruled out in any child with a serious illness [3].

The initial investigations include blood, urine, and cerebrospinal fluid samples for counts and culture; renal ultrasound and voiding cystourethrogram (VCUG) are consequently performed for all those who test positive for UTI [4]. It is crucial to have a clear understanding of the pathogenesis of UTI, risk factors and, indications for diagnostic tests because is that infants with UTI can develop serious complications, such as hypertension and renal insufficiency in adulthood. So, it is mandatory to deeply understand the appropriate uses of antimicrobial agents in the management of children with UTI [5]. Vitamin D is a critical player in the immune regulation, and is thought to have a systemic effect on pathogens $[6,7]$ with a cardinal role in different acute and chronic illnesses. Also, hypocalcemia as a result of vitamin $D$ deficiency further reduces both lymphocyte and neutrophil functions [8]. Barrier defense of cells is also impaired [9]. Recent studies of vitamin D and its receptor (VDR) revealed different cellular functions of VDR that are based on multiple intracellular signaling pathways and molecular targets of this protein. Specifically, VDR appears to regulate molecular composition and functions of different epithelial junctions. VDR has physical interaction with $\beta$-catenin. Activation of VDR suppresses the activity of $\beta$-catenin, thus deceasing nuclear $\beta$-catenin and inhibiting cell proliferation. VDR status is also directly associated with the expression level and functions of tight junction proteins, such as claudin-2 and -12 [10]. An increased VDR level leads to increased claudin-2 and -12, which may play roles in calcium homeostasis and barrier function. The other cell junction proteins involved in vitamin D/VDR include E-cadherin, occludin and ZO-1. Taken together, vitamin D/VDR signaling regulates not only structural integrity but also transport functions of different epithelial barriers $[11,12]$.

Modulation of cytokine responses and reduction of toll-like receptor activation are postulated results of the vitamin $D$ effect on local and systemic inflammatory responses [10]. T-cell activation and the phenotype and function of antigen-presenting cells, especially dendritic cells, are directly influenced by vitamin D [11]. The expression of potent antimicrobial peptides (AMPs), such as cathelicidin and $\beta$-defensin 2 , is also strongly mediated by vitamin $D$ [12].

The results of several studies have shown that vitamin $\mathrm{D}$ and cathelicidin production are closely related. By binding to the vitamin $D$ responsive element (VDRE) of the CAMP promoter vitamin $D$ can induce human cathelicidin gene (CAMP) expression [13-15]. Consequently, increased synthe- sis of cathelicidin after vitamin D treatment has been observed [15].

Vitamin D deficiency has been reported in children with many infections, including recurrent tonsillitis, sepsis, community-acquired pneumonia, and influenza [16]. However, there is no study examining the relationship between UTI, which is a major pediatric health problem, and vitamin $D$ deficiency in children.

We aimed to investigate the association between $25(\mathrm{OH}) \mathrm{D}_{3}$ levels and the risk of first time febrile UTI.

\section{Material and methods}

This controlled prospective study was conducted in the Department of Pediatrics at Suez Canal University Hospital in Ismailia, Egypt, from January 2015 to December 2015. A total of 124 children in the age group from 2 months to 6 years were enrolled. Twenty-four children with first febrile UTI were excluded as they did not meet the inclusion criteria; so, only 100 children were actually included in the study and were divided into two groups:

Group (1): 50 patients experiencing a first episode of febrile UTI, with no risk factors for UTI, in line with the operating definition of UTI. The inclusion criteria for the patients group include: (a) presence of clinical signs and symptoms such as fever ( $\geq 38 \mathrm{c}$ ), abdominal pain, dysuria, anorexia, and nausea, (b) pyuria ( $\geq 5$ white blood cells per high-power field on spun urine), (c) positive urine culture (more than $10^{5}$ colony-forming units (CFUs)/ml of a single pathogen in a midstream clean-void urine sample or $10^{4} \mathrm{CFUs} / \mathrm{ml}$ of a single pathogen in a sample obtained via urinary catheterization) [17], (d) no history of vitamin D supplementation or multivitamins during the last 12 months, (e) average nutritional status with no malnutrition or obesity, and (f) no renal disorders. We further excluded patients with culture results positive for more than one organism, those who had a coexisting morbidity of septicemia, diabetes mellitus, or immune deficiency, and certainly those who had clinical signs of rickets. Patients with congenital anomalies of the kidney and urinary tract, neurogenic bladder, urinary stones, chronic renal failure, and a previous diagnosis of vesicoureteral reflux (VUR) were also excluded.

Group (2): 50 healthy age- and sex-matched siblings were also prospectively included in the study for comparison. The same exclusion criteria were applied for the two groups to rule out all the possible confounding factors that could influence vitamin D levels.

The studied groups were subjected to the following: thorough history taking, clinical examination and laboratory investigations including white 
blood cell (WBC) counts, serum creatinine, blood urea nitrogen (BUN), C-reactive protein (CRP), calcium (Ca), phosphorus (P), alkaline phosphatase (ALP), parathormone (PTH), and $25(\mathrm{OH}) \mathrm{D}_{3}$ levels.

The midstream clean catch method was used to collect urine samples from toilet-trained children and urinary catheters for infants and young children. Specimens were analyzed by standard urinalysis (U/A). To obtain standard U/A, specimens were centrifuged at $2000 \mathrm{rpm}$ for $10 \mathrm{~min}$ and examined microscopically for pyuria [17]. For culture the samples were inoculated on plates containing sheep blood agar and MacConkey agar immediately after their collection. All of the plates were inoculated at $35-37^{\circ} \mathrm{C}$ and examined at 24-48 $\mathrm{h}$ after culturing to determine the colony count as well as bacterial identification. The methods used in the identification and characterization of isolated bacteria include Gram stain followed by microscopic examination, motility test and biochemical tests [18]. The novobiocin susceptibility test was done using a tube method to differentiate coagulase-negative staphylococci (CONS) and identify Staphylococcus saprophyticus and Staphylococcus epidermis (novobiocin-resistant) [18]. Interpretation of the results was done by the hospital medical microbiology staff depending on the collection method and results of the culture and according to the definition of UTI in the inclusion criteria. Even in cases with presumed UTI, when $\mathrm{U} / \mathrm{A}$ results were not conclusive, urine cultures were done [17, 19].

All patients had renal ultrasonography performed within $48 \mathrm{~h}$ of admission. The VCUG was used for selected cases with positive findings on ultrasonography or atypical UTI (seriously ill, poor urine flow, abdominal or bladder mass, raised creatinine, septicemia, failure to respond to correct antibiotic treatment within $48 \mathrm{~h}$, or infection with non-Escherichia coli organisms) [19].

Serum $25(\mathrm{OH}) \mathrm{D}_{3}$ was determined by Immundiagnostik Enzyme-Immuno- Assay (EIA) [20, 21]. Normal range: $25-125 \mathrm{nmol} / \mathrm{l}$. Classification of vitamin D status by $25(\mathrm{OH}) \mathrm{D}_{3}$ concentrations: $\leq 25$ $\mathrm{nmol} / \mathrm{l}$ (deficient), > 25 to $50 \mathrm{nmol} / \mathrm{l}$ (insufficient) and $>50 \mathrm{nmol} / \mathrm{l}$ (optimal) [22].

The Ethics and Human Research Committees of Suez Canal University Hospital approved the study. Informed written consent was obtained from parents of all children. Brief counseling regarding vitamin D deficiency, together with clarification of the aim and method (regarding blood sampling), was given.

\section{Statistical analysis}

The Statistical Package for Social Sciences 21 (SPSS Inc., Chicago, IL, USA) was used for the statistical analysis. Data were expressed as means \pm
SD and percentage. The normality of continuous data was assessed by the Kolmogorov-Smirnov test. $P$-value $<0.05$ was considered statistically significant. The $95 \%$ confidence interval $(\mathrm{Cl})$ was also calculated. Continuous variables were assessed by the independent two samples $t$ test. Categorical variables were compared using the $\chi^{2}$ test.

Pearson correlation analysis was used to evaluate the relationship between $25(\mathrm{OH}) \mathrm{D}_{3}$ levels and demographic variables. Univariate logistic regression analysis was used to determine the strength of the relationship between the risk factors for UTI, namely age, gender, WBC count, serum CRP, and $25(\mathrm{OH}) \mathrm{D}_{3}$ values. A risk factor associated with a $p$-value of $<0.05$ in the univariate analysis was used for further investigation. A multivariate logistic regression analysis was performed to determine the association between risk factors and UTI. A $p$-value of $<0.05$ was considered statistically significant.

\section{Results}

During the period from January 2015 to December 2015, 74 children presented with their first febrile UTI. Five caregivers refused to sign the consent and were not willing to participate in the study, 1 patient was found to have a solitary kidney, 2 patients with hydronephrosis and 10 patients had a history of vitamin $D$ supplementation within the last 12 months, and so 18 patients were initially excluded from the study. Of the remaining 56 patients, 6 were found to have different grades of VUR by VCUG and were also excluded. Only 50 patients who met the inclusion criteria were included in the study with another 50 controls.

Gender and age were successfully matched between cases and controls. Data of the study were normally distributed and expressed as mean \pm SD. The mean \pm SD age of cases was $0.98 \pm 1.15$ years, and that of controls was $0.90 \pm 1.23$ years ( $p>0.05)$. Among the 50 children with UTI, 30 (60\%) were girls and 20 (40\%) were boys, giving a female to male ratio of $3: 2$. In the control group 32 (64\%) were female and 18 (36\%) were male. There was no statistically significant difference in serum $\mathrm{Ca}, \mathrm{P}$, and ALP levels in the study group compared to the control group $(p>0.05)$.

Regarding the results of the current study, comparison between the UTI group and the control group as regards the mean serum levels of $25(\mathrm{OH}) \mathrm{D}_{3}$ showed that it was significantly lower in the study group than in the control group $(10.5 \pm 2.7 \mathrm{nmol} / \mathrm{l}$ and $25.9 \pm 5.6 \mathrm{nmol} / \mathrm{l}$, respectively) $(p<0.05)$ (Table I).

Insufficient serum $25(\mathrm{OH}) \mathrm{D}_{3}$ levels $(\leq 25 \mathrm{nmol} / \mathrm{l})$ were found in 19 (38\%) of the 50 patients with UTI, and in only $6(12 \%)$ controls. Thus, insufficient levels of $25(\mathrm{OH}) \mathrm{D}_{3}$ were significantly more 
Table I. Comparison of demographic characteristics and laboratory parameters between cases with UTI and controls

\begin{tabular}{|c|c|c|c|}
\hline Parameter & $\begin{array}{l}\text { Patients } \\
N=50\end{array}$ & $\begin{array}{c}\text { Controls } \\
N=50\end{array}$ & $P$-value \\
\hline Females & $30(60 \%)$ & $32(64 \%)$ & $0.216^{\#}$ \\
\hline Age, mean \pm SD [years] & $0.98 \pm 1.15$ & $0.90 \pm 1.23$ & 0.336 \\
\hline $25(\mathrm{OH}) \mathrm{D}_{3}$, mean $\pm \mathrm{SD}[\mathrm{nmol} / \mathrm{l}]$ & $10.5 \pm 2.7$ & $27.9 \pm 5.6$ & $<0.001^{\star}$ \\
\hline $\mathrm{PTH}$, mean $\pm \mathrm{SD}[\mathrm{pg} / \mathrm{ml}]$ & $40.2 \pm 15.9$ & $2.4 \pm 15.0$ & 0.017 \\
\hline CRP, mean $\pm \mathrm{SD}[\mathrm{mg} / \mathrm{dl}]$ & $20.9 \pm 15.7$ & $2.0 \pm 0.5$ & $<0.001^{\star}$ \\
\hline WBC, mean $\pm S D\left[\mathrm{n} / \mathrm{mm}^{3}\right]$ & $16.23 \pm 3.34$ & $5.98 \pm 0.98$ & $<0.001^{*}$ \\
\hline
\end{tabular}

P-value is significant at $<0.05$ level, * Significant.

frequent in the UTI group than in the control group $(p=0.031)$. Deficient levels $(<25 \mathrm{nmol} / \mathrm{l})$ were significantly more frequent among the UTI group (20\%), while they were found in only $6 \%$ of the control group $(p=0.011)$. There was no correlation between serum $25(\mathrm{OH}) \mathrm{D}_{3}$ levels and age in either group $(r=-0.113 ; p=0.232)$.

Univariate analysis showed a significant association between WBC count, serum CRP, and $25(\mathrm{OH}) \mathrm{D}_{3}$ values in the patient group. Within the study group, mean serum levels of $25(\mathrm{OH}) \mathrm{D}_{3}$ were $11.1 \pm 2.7 \mathrm{nmol} / \mathrm{l}$ in girls and $14.0 \pm 3.9 \mathrm{nmol} / \mathrm{l}$ in boys. The levels were significantly lower in girls within the study group. However, the serum levels of $25(\mathrm{OH}) \mathrm{D}_{3}$ were similar between boys and girls in the control group $(p=0.523)$. The mean serum levels of $25(\mathrm{OH}) \mathrm{D}_{3}$ were $7.9 \pm 3.7 \mathrm{nmol} / \mathrm{l}$ for children with APN and $13.7 \pm 2.9 \mathrm{nmol} / /$ for children with lower UTI $(p<0.001)$. The levels were significantly lower in patients with APN compared to patients with lower UTI.

The serum levels of PTH were significantly higher in the patient group $(40.2 \pm 15.9 \mathrm{pg} / \mathrm{ml})$ compared to the control group $(2.4 \pm 15.0 \mathrm{pg} / \mathrm{ml})$ $(p=0.017)$.

The APN was diagnosed in 32 children (20 female and 12 male), while lower UTI was diagnosed in 18 children (10 female and 8 male). There was no statistically significant difference between the APN and lower UTI patients in terms of age and gender $(p>0.05)$ (Table II).

Fever was the most frequent presenting symptom $(97.0 \%)$ in UTI patients, followed by ab-

Table II. Age distribution of patients according to site of UTI

\begin{tabular}{|lccc|}
\hline $\begin{array}{l}\text { Age } \\
\text { [years] }\end{array}$ & $\begin{array}{c}\text { APN }=32 \\
\text { female (20)/ } \\
\text { male (12) }\end{array}$ & $\begin{array}{c}\text { Lower UTI =18 } \\
\text { female (10)/ } \\
\text { male (8) }\end{array}$ & P-value \\
\cline { 1 - 3 }$<1$ & $4 / 7$ & $3 / 2$ & \\
\cline { 1 - 3 } $1-3$ & $12 / 3$ & $5 / 5$ & \\
\cline { 1 - 3 } 3 & $4 / 2$ & $2 / 1$ & \\
\hline
\end{tabular}

dominal pain (90.0\%), anorexia (82.0\%), dysuria (75.0\%) and lastly nausea (50.0\%). There was no reported change in renal functions including serum BUN, creatinine levels, and creatinine clearance rate in all patients (Data not shown).

Among the causative organisms Escherichia coli was the most common in both APN and lower UTI patients and accounted for $78.0 \%$ and $89.0 \%$ of cases respectively, Klebsiella was second in rank in APN with $11 \%$, followed by Proteus (6\%), Staphylococcus (3\%) and Pseudomonas (2\%), while in lower UTI Klebsiella accounted for 6\%, Proteus $4 \%$ and Staphylococcus 1\%. Staphylococcus includes the three species S. aureus, S. epidermidis and S. saprophyticus.

In the patient group, the multivariate logistic regression analysis showed that a serum level of $25(\mathrm{OH}) \mathrm{D}_{3} \leq 25 \mathrm{nmol} / \mathrm{l}(\mathrm{OR}=1.94,95 \% \mathrm{Cl}: 1.61-$ 2.82; $p=0.04)$, and CRP > $3 \mathrm{mg} / \mathrm{dl} I(\mathrm{OR}=4.00$, 95\% Cl: 3.40-4.62; $p=0.001$ ) have a significant association with UTI. The multivariate analysis results are shown in Table III.

\section{Discussion}

The results of the current prospective study showed that vitamin D deficiency in children was independently associated with UTI. Throughout the previous years many studies have provided increased evidence of the role of vitamin D deficiency in worsening outcomes and increasing the susceptibility to infections [7-11]. Apart from its established role in maintaining bone health, vitamin D plays a crucial role in enhancing the innate

Table III. Results of the multivariate analysis of UTI among children

\begin{tabular}{|lcc|}
\hline Variable & OR $(95 \% \mathrm{Cl})$ & $P$-value \\
\hline $\begin{array}{l}25(\mathrm{OH}) \mathrm{D}_{3} \\
\text { of } \leq 25 \mathrm{nmol} / \mathrm{l}\end{array}$ & $3.503(1.621-7.571)$ & $0.001^{*}$ \\
\hline $\mathrm{WBC}>12,000 / \mathrm{mm}^{3}$ & $0.815(0.710-1.005)$ & 0.183 \\
\hline $\mathrm{CRP}>3 \mathrm{mg} / \mathrm{dl}$ & $1.016(1.012-1.020)$ & $<0.001^{*}$ \\
\hline
\end{tabular}


immunity and potentiating antimicrobial actions against different organisms, such as bacteria, viruses and fungi. The existing evidence for an indirect antimicrobial effect of vitamin $D$ is compelling [10-16]. The problem of increased resistance of microorganisms to current antibiotics has become increasingly serious and is now seen as a major public health threat [12]. Lately, AMPs have received a lot of attention as new antimicrobial alternatives, which microbes are less prone to develop resistance towards. Unlike conventional antibiotics which microbes readily circumvent, resistance development by a sensitive microbial strain against antimicrobial peptides is less probable [13]. This is mainly due to the deep changes in the membrane structure needed to confer resistance [12]. Synergy between AMPs and small molecule antibiotics has been observed. As an example, AMPs can help antibiotics to regain their antimicrobial effect by the blockage of efflux pumps in Gram-negative antibiotic resistant strains. Consequently, synergistic effects can be an approach in the limitation of resistance development [12-15].

There is a rapidly growing belief that patients' outcomes could be improved by intensive vitamin D supplementation before and during hospital stays [23]. Fortunately, considering its cheap price, vitamin $\mathrm{D}$ supplementation could be provided at a reasonable cost. Nowadays, it is a usual practice to prescribe traditional antimicrobials for infectious processes. Inappropriate antibiotic prescription could be minimized by combining use of vitamin D as an inexpensive prophylactic option together with the appropriate antibiotic. This may result in a significant reduction in the misuse of antibiotics and antibiotic resistance contributing to escalating health care costs. Infections of the urinary tract induce epithelial cells to produce cathelicidin, protecting against bacterial infection to protect the urinary tract from bacterial adherence [24]. Epithelium-derived cathelicidin, therefore, seems to have an important role in the first line of defense against attacking bacteria, despite its low concentration [13-15]. Cathelicidin has a defined vitamin D-dependent mechanism. In response to the success of bacteria to adhere to the wall of the urinary tract, the epithelial cells substantially increased the synthesis and secretion of cathelicidin [25]. Later on, with the progress of the inflammatory process, the inflammatory peptide cathelicidin is produced by the invading leukocytes [24]. Recent studies have shown that uropathogenic $E$. coli strains resistant to human cathelicidin were more prone to invade the upper urinary tract than susceptible strains. Sufficient concentrations of circulating vitamin $D$ are mandatory for optimal cathelicidin production by macrophages [26, 27]. On the background of this evidence, the link between vitamin D and UTIs was examined [15, 27-30]. In their attempt to illustrate the role of vitamin $\mathrm{D}$ in protecting against UTIs, Hertting et al. [15] found that production of cathelicidin significantly increased in bladders infected with uropathogenic $E$. coli after vitamin $D_{3}$ supplementation. They stated that: "In the light of the rapidly growing problem of resistance to common urinary tract antibiotics, vitamin $D$ may be a potential complement in the prevention of UTI. Determining the vitamin D status of individuals with a history of UTI may be of importance to evaluate their ability to fend off intruding bacteria". This means that vitamin D has a huge advantage over mainstream medicine's widely prescribed antibiotics for urinary tract infections. That is because when UTIs are treated with antibiotics, the drugs can harm beneficial bacteria in the gut and elsewhere in the body. But vitamin D only produces local germ-killing peptides at the site of an infection when needed, leaving "friendly bacteria" totally unharmed [15].

Furthermore, the adaptive immune system requires optimal levels of vitamin $D$ to operate. 1,25-dihydroxyvitamin targets several identified genes in mature T helper cells [12]. Genetic susceptibility to UTI and renal scar formation have been linked to vitamin $D$ receptor gene polymorphisms [28]. To date, there is no established evidence regarding the relationship between vitamin D deficiency and UTI in children. In a trial to clarify this relationship we hypothesized that vitamin $D$ deficiency may have a role in the development of UTI in children and investigated the association between $25(\mathrm{OH}) \mathrm{D}_{3}$ levels and UTI in children. We studied 50 children with UTI, and 50 age- and sex-matched healthy control children. To eliminate all the demographic and epidemiological factors, we selected the control group from the patients' own siblings. The selection of the age group of (2 months -6 years) was intended to enroll children during the peak age at which they have the highest likelihood to develop UTI. Timing of UTI in children follows a bimodal distribution with the first wave of infections in the first year of life and another peak of infections at the age of toilet training between 2 and 4 years of age $[3,4]$. After 6 years of age and early adulthood, new-onset UTIs in children are relatively infrequent and often associated with dysfunctional elimination or initiation of sexual intercourse after puberty [5].

In spite of the strong evidence that girls are more likely to have UTIs than boys, we recruited both genders to increase the generalizability of the study findings. However, the ratio of female participants was still significantly higher in the study group, which limited the results of our study. Our results showed that the serum level of $25(\mathrm{OH}) \mathrm{D}_{3}$ in children with UTI was significantly lower than in healthy children $(p<0.001)$. Insufficient levels 
of $(\leq 25 \mathrm{nmol} / \mathrm{l})$ were significantly more frequent (38\%) in patients with UTI, compared with controls $(12 \%)(p=0.031)$. We proved that a serum level of $25(\mathrm{OH}) \mathrm{D}_{3}(\leq 25 \mathrm{nmol} / \mathrm{l})$ is associated with $\mathrm{UTI}(\mathrm{OR}=1.94,95 \% \mathrm{Cl}: 1.61-2.82 ; p=0.04)$.

In agreement with our results, a recently published Turkish study of 82 children experiencing a first episode of UTI, with no risk factors for UTI, and 64 healthy control children showed that a serum level of $25(\mathrm{OH}) \mathrm{D}_{3}<20 \mathrm{nmol} / \mathrm{l}$ is associated with UTI (OR $=3.503,95 \% \mathrm{Cl}: 1.621-7.571 ; p=$ $0.001)$. Children with serum levels of $25(\mathrm{OH}) \mathrm{D}_{3}$ $<20 \mathrm{nmol} / \mathrm{l}$ are 3.5 times more likely to develop UTI than those with normal levels [30].

Furthermore, a group of researchers conducted a retrospective study, aimed at examining the association between serum $25(\mathrm{OH})$ vitamin D levels and recurrent UTIs in premenopausal women, and found that a deficient serum $25(\mathrm{OH}) \mathrm{D}_{3}$ level of $<15 \mathrm{nmol} / \mathrm{l}(\mathrm{OR}=4.00,95 \% \mathrm{Cl}: 3.40-4.62 ; p=$ 0.001 ) was associated with recurrent UTIs in premenopausal women [29]. In the current study, we subdivided the patient group into patients with APN (32), and patients with lower UTI (18); we also investigated serum $25(\mathrm{OH}) \mathrm{D}_{3}$ levels in APN and lower UTI. There were statistically significantly lower values of $25(\mathrm{OH}) \mathrm{D}_{3}$ in APN $(p<0.001)$. In accordance with the Turkish study [15] our results showed that serum levels of $25(\mathrm{OH}) \mathrm{D}_{3}$ in girls within the UTI group were significantly lower when compared with those of boys ( $p=0.001$ ). The Turkish authors did not give any justification for this difference. From our point of view our results could be partly explained based on the age distribution of our UTI patients, as 12 (40\%) out of the 30 recruited girls were in the age group of $1-3$ years while only 4 (25\%) out of the 20 boys were in the same age group; Egypt is one of the countries with high breastfeeding rates; the chaos is due in part to the country's generally poor population. Luckily, a significant amount of mothers in Egypt have been properly informed about the benefits of breastfeeding; an educational program was developed to target mothers of preterm infants, a program which was successful in improving breastfeeding knowledge and practice among all Egyptian mothers in general [6]. For each additional month of breastfeeding beyond a year of age, the vitamin $\mathrm{D}$ level goes down and it keeps going down, but for children who are continuing to receive vitamin $D$ supplementation, the vitamin $D$ level in their blood does not go down. The researchers from St. Michael's Hospital and the Hospital for Sick Children, Toronto, Canada found that the risk of vitamin $D$ deficiency rose by $6 \%$ for every month that babies were breastfed past age 1 . By age 2 , they had a $16 \%$ chance of being deficient and by 3 it was $29 \%$. That is because while they still benefit from breast milk, nursing toddlers may not consume as much of foods such as cow's milk and other dietary sources of the vitamin as needed [31]. A cited study which addressed the predictors of serum 25-hydroxyvitamin D concentrations among a sample of Egyptian schoolchildren reported similar results; the authors stated that the difference in gender may be due to lifestyle factors such as spending more time indoors, less time outdoors, and coverage of skin by clothing that could affect cutaneous synthesis of vitamin D [32]. However, this cannot be applied to our population due to the younger age of girls in the current study, as none of them wear a hijab.

Several studies have found a significant positive correlation between UTI and CRP, but none with WBC [30, 33, 34]. Researchers concluded that CRP is a suitable marker for diagnosis of UTI. Consistent with those previous studies, we found that CRP levels were higher in patients with UTI than in the healthy group and levels $>3 \mathrm{mg} / \mathrm{dl}$ (OR $=1.016,95 \% \mathrm{Cl}: 1.012-1.020 ; p<0.001)$ were found to be associated with UTI.

In conclusion, vitamin D deficiency was found to be associated with UTI in children. The serum levels of $25(\mathrm{OH}) \mathrm{D}_{3}$ were significantly lower in patients with APN compared to patients with lower UTI. These results suggest that vitamin D deficiency may be a risk factor for UTI in children. More studies are needed to validate these data and to assess whether correction of $25(\mathrm{OH}) \mathrm{D}_{3}$ serum levels may prevent UTIs.

\section{Conflict of interest}

The authors declare no conflict of interest.

\section{References}

1. Shaikh N, Ewing AL, Bhatnagar S, Hoberman A. Risk of renal scarring in children with a first urinary tract infection: a systematic review. Pediatrics 2010; 126: 1084-91.

2. Finnell SM, Carroll AE, Downs SM. Subcommittee on Urinary Tract I. Technical report-diagnosis and management of an initial UTI in febrile infants and young children. Pediatrics 2011; 128: e749-70.

3. Subcommittee on Urinary Tract Infection, Steering Committee on Quality Improvement and Management. Roberts KB. Urinary tract infection: clinical practice guideline for the diagnosis and management of the initial UTI in febrile infants and children 2 to 24 months. Pediatrics 2011; 128: 595-610.

4. American Academy of Pediatrics Committee on Quality Improvement, Subcommittee on Urinary Tract Infection. Practice parameter: the diagnosis, treatment, and evaluation of the initial urinary tract infection in febrile infants and young children. Pediatrics 1999; 103: 843-52.

5. Keren R, Carpenter MA, Hoberman A, et al. Rationale and design issues of the Randomized Intervention for Children With Vesicoureteral Reflux (RIVUR) Study. Pediatrics 2008; 122: 240-50. 
6. Katikaneni R, Ponnapakkam T, Ponnapakkam A, Gensure R. Breast feeding does not protect against urinary tract infection in the first 3 months of life, but vitamin D supplementation increases the risk by $76 \%$. Clin Pediatr 2009; 48: 750-5.

7. Holick MF. Vitamin D deficiency. N Engl J Med 2007 . 357: 266-81.

8. Gombart AF. The vitamin D-antimicrobial peptide pathway and its role in protection against infection. Future Microbiol 2009; 4: 1151-65.

9. Adams JS, Hewison M. Update in vitamin D. J Clin Endocrinol Metabol 2010; 95: 471-8.

10. Jeng L, Yamshchikov AV, Judd SE, et al. Alterations in vitamin D status and anti-microbial peptide levels in patients in the intensive care unit with sepsis. J Transl Med 2009; 7: 28.

11. Canning MO, Grotenhuis K, de Wit H, Ruwhof C, Drexhage HA. 1-alpha,25-Dihydroxyvitamin D3 $\left(1,25(\mathrm{OH})_{2} \mathrm{D}_{3}\right)$ hampers the maturation of fully active immature dendritic cells from monocytes. Eur J Endocrinol 2001; 145: 351-7.

12. Bartley J. Vitamin D: emerging roles in infection and immunity. Expert Rev Anti Infect Ther 2010; 8: 1359-69.

13. Wang TT, Nestel FP, Bourdeau V, et al. Cutting edge: 1,25-dihydroxyvitamin $D_{3}$ is a direct inducer of antimicrobial peptide gene expression. J Immunol 2004; 173: 2909-12.

14. Liu PT, Stenger S, Li H, et al. Toll-like receptor triggering of a vitamin D-mediated human antimicrobial response. Science 2006; 311: 1770-3.

15. Hertting O, Holm Å, Lüthje P, et al. Vitamin D induction of the human antimicrobial peptide cathelicidin in the urinary bladder. Bereswill S (ed.). PLoS One 2010; 5: e15580.

16. Toubi E, Shoenfeld $Y$. The role of vitamin $D$ in regulating immune responses. Isr Med Assoc J 2010; 12: 174-5.

17. Edefonti A, Tel F, Testa S, De Palma D. Febrile urinary tract infections: clinical and laboratory diagnosis, imaging, and prognosis. Semin Nucl Med 2014; 44: 123-8.

18. Williams GJ, Macaskill P, Chan SF, Turner RM, Hodson E, Craig JC. Absolute and relative accuracy of rapid urine tests for urinary tract infection in children: a meta-analysis. Lancet Infect Dis 2010; 10: 240-50.

19. National Institute for Health and Care Excellence. Urinary tract infection in under 16s: diagnosis and management 2015. Available from URL: http://www.guidelines.co.uk/nice/uti-children

20. Scharla SH, Scheidt-Nave C, Leidig G, et al. Lower serum 25-hydroxyvitamin $D$ is associated with increased bone resorption markers and lower bone density at the proximal femur in normal females: a population-based study. Exp Clin Endocrinol Diabetes 1996; 104: 289-92.

21. Scharla SH. Prevalence of subclinical vitamin D deficiency in different European countries. Osteoporos Int 1998; 8: 7-12.

22. Soliman GT, Ali BA, Mohamed AA, Mahmoud AM, Abdellatif AA. Assessment of vitamin D status in Egyptian children with type-1 diabetes mellitus. J Diabetes Metab 2015; 6: 573.

23. Youssef DA, Ranasinghe T, Grant WB, Peiris AN. Vitamin D's potential to reduce the risk of hospital-acquired infections. Dermatoendocrinology 2012; 4: 167-75.

24. Zasloff M. Antimicrobial peptides of multicellular organisms. Nature 2002; 415: 389-95.

25. Chromek M, Slamova Z, Bergman P, et al. The antimicrobial peptide cathelicidin protects the urinary tract against invasive bacterial infection. Nature Med 2006; 12: 636-41.

26. Norden CW, Green GM, Kass EH. Antibacterial mechanisms of the urinary bladder. J Clin Investig 1968; 47: 2689-700.

27. Justice SS, Hung C, Theriot JA, et al. Differentiation and developmental pathways of uropathogenic Escherichia coli in urinary tract pathogenesis. Proc Natl Acad Sci USA 2004; 101: 1333-8.

28. Aslan S, Akil I, Aslan G, Onay H, Ozyurt BC, Ozkinay F. Vitamin $D$ receptor gene polymorphism in children with urinary tract infection. Pediatr Nephrol 2012; 27: 417-21.

29. Nseir W, Taha M, Nemarny H, Mograbi J. The association between serum levels of vitamin $D$ and recurrent urinary tract infections in premenopausal women. Int J Infect Dis 2013; 17: 1121-4.

30. Tekin M, Konca C, Celik V, et al. The association between vitamin $\mathrm{D}$ levels and urinary tract infection in children. Horm Res Paediatr 2015; 83: 198-203.

31. Darmawikarta D, Chen Y, Lebovic G, Birken CS, Parkin PC, Maguire JL. Total duration of breastfeeding, vitamin D supplementation, and serum levels of 25-hydroxyvitamin D. Am J Public Health 2016; 106: 714-9.

32. Abu Shady MM, Youssef MM, Salah El-Din EM, et al. Predictors of serum 25-hydroxyvitamin D concentrations among a sample of Egyptian schoolchildren. Sci World J 2016 in press doi:10.1155/2016/8175768.

33. Gurgoze MK, Akarsu S, Yilmaz E, et al. Proinflammatory cytokines and procalcitonin in children with acute pyelonephritis. Pediatr Nephrol 2005; 20: 1445-8.

34. Ayazi P, Mahyar A, Daneshi MM, Jahani Hashemi H, Pirouzi $M$, Esmailzadehha N. Diagnostic accuracy of the quantitative C-reactive protein, erythrocyte sedimentation rate and white blood cell count in urinary tract infections among infants and children. Malays J Med Sci 2013; 20: 40-6. 